\title{
EVALUACIÓN AMBIENTAL DEL FENÓMENO "EL NIÑO 1997-98" EN EL SECTOR AGRARIO
}

\section{ENVIRONMENTAL ASSESSMENT OF "EL NIÑO 1997-98" IN AGRICULTURAL SECTOR Luis Garnica}

El fenómeno "El Niño", ocurrido en como excepcional debido a las altas nuestro país durante el periodo $1997-98$, precipitaciones y elevadas temperaturas presentó características meteorológicas y registradas en diversas zonas del país, océano-atmosféricas que permiten tipificarlo principalmente en la costa norte.

Tabla 1. Evaluación ambiental de las consecuencias del fenómeno "El Niño 1997-98" en el sector agrario del Perú.

\section{Principales consecuencias}

- Áreas agrícolas afectadas por inundación.

- Deterioro y destrucción de infraestructura de riego.

- Alteración del desarrollo normal de cultivos por la elevada temperatura.

- Incremento de plagas agrícolas.

- Incremento de aguas almacenadas en los reservorios de la costa norte.

- Aparición de la laguna "La Niña".

- Alteración en el comportamiento de flora y fauna.

- Incremento de recarga hídrica en acuíferos subterráneos.

- Lavado de suelos salinos.

Estas condiciones excepcionales han afectado a diversas actividades económicoproductivas y el sector agrario figuró entre los de mayor impacto (Tab. 1). Las elevadas precipitaciones registradas en la zona norte y

Director General del Medio Ambiente Rural Ministerio de Agricultura Instituto Nacional de Recursos Naturales área altoandina, los excepcionales volúmenes de agua aforados en los ríos de la costa y las temperaturas ambientales por encima de los valores históricos registrados, redundaron en pérdidas de áreas agrícolas y reducción de la producción agrícola nacional. Asimismo, causaron alteraciones en el comportamiento normal de la flora y fauna en diversas zonas del país. 
Tabla 2. Pérdidas económicas inducidas por "El Niño 1997-98" en el territorio peruano, por zonas geográficas.

\begin{tabular}{|c|c|c|c|c|}
\hline \multirow{2}{*}{ Zona geográfica } & \multicolumn{3}{|c|}{ Superficie (ha) } & \multirow{2}{*}{$\begin{array}{c}\text { Valor } \\
\text { Miles US\$ }\end{array}$} \\
\hline & Total & Pérdida & Afectada & \\
\hline Norte & 57043 & 29692 & 27351 & 65169 \\
\hline Centro & 55741 & 13929 & 41812 & 62334 \\
\hline Sur & 75944 & 16355 & 59639 & 42687 \\
\hline Oriente & 15413 & 13070 & 2342 & 8107 \\
\hline Nacional & 204191 & 73047 & 131144 & 178297 \\
\hline
\end{tabular}

Fuente: Ministerio de Agricultura

Superficie Perdida: La producción se perdió completamente

Superficie Alterada: La producción disminuyó en rendimiento

Tabla 3. Consecuencias negativas de "El Niño 1997-98" en áreas agrícolas del norte del Perú.

\begin{tabular}{lrcrrr}
\hline \multirow{2}{*}{ Zona } & \multicolumn{3}{c}{ Superficie (ha) } & \multicolumn{2}{c}{ Valor } \\
\cline { 2 - 5 } & \multicolumn{1}{c}{ Total } & Pérdida & Alterada & Miles US\$ & $\%$ \\
\hline Nacional & 204191 & 73047 & 131144 & 178279 & 100,0 \\
Norte & 57043 & 29692 & 27351 & 65169 & 36,6 \\
Tumbes & 4989 & 4483 & 506 & 6887 & 10,6 \\
Piura & 11078 & 6844 & 4234 & 17244 & 26,5 \\
Lambayeque & 15257 & 6885 & 8372 & 15363 & 23,6 \\
La Libertad & 17300 & 6328 & 10972 & 21014 & 32,0 \\
Cajamarca & 7945 & 4882 & 3063 & 4103 & 6,3 \\
Amazonas & 476 & 272 & 204 & 558 & 0,9 \\
\hline
\end{tabular}

Fuente: Ministerio de Agricultura

Superficie Perdida: La producción se perdió completamente

Superficie Alterada: La producción disminuyó en rendimiento

De acuerdo a cifras preparadas por el Ministerio de Agricultura, a nivel nacional fueron afectadas 204191 ha de superficie agrícola, de las cuales en 73047 ha se perdió la producción y en las 131144 ha restantes disminuyó el rendimiento normal. Esto significó económicamente una pérdida de 178297000 dólares (Tab. 2). A nivel departamental, en la costa norte, La Libertad fue la zona con la mayor superficie agrícola impactada desfavorablemente por el fenómeno "El Niño", con 17300 ha, lo cual significó una pérdida de 21014000 dólares en producción agrícola (Tab. 3 ).

Respecto al comportamiento de la flora y fauna, el seguimiento realizado en áreas naturales protegidas del Perú, permitió identificar impactos positivos, como el incremento de flora andina y abundante presencia de aves migratorias, así como la recuperación de pastizales en el Parque Nacional del Huascarán. Sin embargo, entre los impactos negativos, tenemos la mortandad y alteración de hábitats por condiciones meteorológicas extremas, de los lobos marinos asentados en la Reserva Nacional de Paracas (Tab. 4).

Como aprovechamiento de las condiciones excepcionales de humedad generadas por "EI Niño", el Proyecto Algarrobo efectuó la 
Tabla 4. Alteraciones observadas en las áreas naturales protegidas del Perú durante "El Niño 1997-98".

\begin{tabular}{|c|c|}
\hline Área protegida & Alteración \\
\hline Parque Nacional del Huascarán & $\begin{array}{l}\text { Incremento de flora andina y aves. } \\
\text { Incremento de agua en lagunas. } \\
\text { Deterioro carretera a Pastoruri. }\end{array}$ \\
\hline Parque Nacional Rio Abiseo & $\begin{array}{l}\text { Aumento de flora y fauna. } \\
\text { Ausencia de caza, pesca y quema de pastos. } \\
\text { Averia de caminos y deslizamiento de laderas. }\end{array}$ \\
\hline Reserva Nacional de Paracas & $\begin{array}{l}\text { Afectación de niveles reproductivos y comportamiento } \\
\text { migratorio de lobos marinos. } \\
\text { Migración de peces ocasionó mortandad en lobos } \\
\text { marinos y aves (guanay, piquero común, pelícano). }\end{array}$ \\
\hline Reserva Nacional de Lachay & $\begin{array}{l}\text { Desarrollo de algunas especies de flora. } \\
\text { Presencia de aves migratorias. } \\
\text { Impacto del clima en el cielo vital de la vegetación. }\end{array}$ \\
\hline Reserva Nacional de Titicaca & $\begin{array}{l}\text { Recuperación del nivel del Lago Titicaca por aumento } \\
\text { de precipitaciones. } \\
\text { Impacto del clima en el cielo vital de la vegetación. }\end{array}$ \\
\hline Zona Reservada de Pantanos de Villa & $\begin{array}{l}\text { Presencia de aves migratorias del norte, adelantando } \\
\text { su periodo de visita. }\end{array}$ \\
\hline
\end{tabular}

siembra de semillas de especies vegetales en amplias zonas de la costa norte: Tumbes 50000 ha, Piura 150000 ha, Lambayeque 60000 (Mórrope), etc. Hasta el 15 de marzo de 1998 , se tenía programada la siembra de 385000 ha en la costa norte, de las cuales 344000 ha fueron teminadas.

Asimismo, como parte del aprovechamiento mencionado, se tiene proyectada lá utilización de los recursos hídricos excedentes generados, mediante la perforación de pozos a ser utilizados para la recarga hídrica del acuífero subterráneo en el
Departamento de Piura (parte baja).

Entre las principales medidas de rehabilitación previstas por el sector agrario, se programó la realización de diversas obras relacionadas con la recuperación de la infraestructura hidráulica, afectada por caudales excepcionales, tales como: limpieza y descolmatación de canales de riego principales y laterales, descolmatación y reparación de taludes en drenes principales, reparación de bocatomas rústicas y muros de contención, instalación de compuertas, rehabilitación de pozos tubulares, etc. 